\title{
IMPROVEMENT OF THE BIOAVAILABILITY OF BUSPIRONE HCL USING INTRANASAL DELIVERY SYSTEMS
}

\author{
Hamza N. Bshara, Rihab O. Ahmed, Samar M. Holayel, Abd El-Hamid A. El-Shamy \\ Department of Pharmaceutics and Industrial Pharmacy, Faculty of Pharmacy, Ain Shams University, \\ Monazamet El Wehda El Afrikia St., El Abbassia, Cairo, Egypt.
}

\begin{abstract}
The purpose of the present study was to improve the bioavailability of buspirone hydrochloride using oil-in-water microemulsion, which was suggested to be suitable for intranasal delivery. Different pseudo-ternary phase diagrams were constructed to determine the microemulsion existing zone. The optimized microemulsion system was chosen. Different formulations were thus prepared and they were subsequently characterized for their polarized light microscopy, \% transmittance, droplet size, and $\mathrm{pH}$. An optimal microemulsion formulation consisting of 5\% isopropyl myristate, 50\% water, and $45 \%(\mathrm{w} / \mathrm{w})$ surfactant/cosurfactant [Tween $8030 \%$, propylene glycol $15 \%$ at 2: 1 weight ratio] was transparent with \% transmittance $99.52 \pm 0.43 \%$, mean globule size $35.1 \pm 0.5 \mathrm{~nm}$, and $\mathrm{pH} 6.4$ \pm 0.03 , was thus selected for preparation of buspirone microemulsion formulation. Drug release was carried out using modified Franz diffusion cell. Various pharmacokinetic parameters including $\mathrm{C}_{\max }, \mathrm{t}_{\max }$ and $\mathrm{AUC}_{0-\mathrm{t}}$ were determined using Wister albino rats as the animal model. The absolute bioavailability $(0-6 \mathrm{~h})$ was $15.85 \%$ compared to the intravenous administration in rats, whereas the oral bioavailability of buspirone hydrochloride was $4 \%$. The results confirmed that the suggested intranasal buspirone microemulsion formulations improved to a much promising extent its bioavailability.
\end{abstract}

Key words: Intranasal delivery (IN); Microemulsion (ME); Buspirone Hydrochloride (BH); bioavailability (BAV).

\section{INTRODUCTION}

In recent years, the nasal route has received great attention because of the large surface area of the nasal mucosa and the relatively high blood flow, thereby achieving a rapid absorption and avoiding the hepatic first-pass elimination (Lin et al., 2007).

Carrier systems play an important role in the drug delivery to the target site because a dosage form with poor drug delivery can make a useful drug worthless. Microemulsions (MEs) offer an interesting and potentially powerful carrier system for drug delivery because of their high solubilization capacity, transparency, thermodynamic stability, ease of preparation, in addition to the high diffusion and absorption rates (Jadhav et al., 2006; Yin $\boldsymbol{e t}$ al., 2009).

Buspirone $\mathrm{HCl}(\mathrm{BH})$, the psychotropic drug with selective anxiolytic properties, belongs chemically to the class of azaspirodecanediones which are not chemically or pharmacologically related to benzodiazepines. It seems to be a promising candidate for the intranasal delivery owing to its extensive first-pass metabolism resulting in the poor oral bioavailability of the pure drug $(\sim 4 \%)$, in addition to a short half-life and the poor lower gastrointestinal tract absorption values (Galichet, 2004). Based on this, the present study aims was to improve $\mathrm{BH}$ bioavailability using $\mathrm{ME}$ that may help maximize the therapeutic index of the drug, reduce its side effects, its dose and its frequency of dosing that may result in a cost-effectiveness treatment intervention (Zhang et al., 2004). 


\section{EXPERIMENTAL}

\section{Materials:}

BH was kindly supplied by Bristol Myers Squibb (Cairo, Egypt). Jojoba oil was kindly supplied by the Egyptian Oil Company (Cairo, Egypt). Isopropyl myristate (IPM), Acetonitrile (HLPC grade), Methanol were purchased from Sigma-Aldrich (St. Louis, USA). Diltiazim (DILT) was kindly supplied by E.P.I.C.O (Cairo, Egypt). Labrafac ${ }^{\circledR}$ Lipophile WL1349 (Labr), Diethylene glycol monoethyl ether "Transcutol ${ }^{\circledR}$ ", Caprylocaproyl macrogol8 glycerides "Labrasol ${ }^{\circledR} "$ were kindly supplied by Gattefosse (Saint-Priest, Lyon, France). Polyethylene 80 sorbitan monooleate "Tween $80^{\circledR} "$ (T80), Isopropyl alcohol, Propylene glycol (PG), Disodium hydrogen phosphate $\left(\mathrm{Na}_{2} \mathrm{HPO}_{4}\right)$, Potassium dihydrogen phosphate $\left(\mathrm{KH}_{2} \mathrm{PO}_{4}\right)$ were purchased from Adwic and El-Nasr Chemical Co, (Cairo, Egypt).

\section{Equipment:}

Horizontal mechanical shaker (Kötterman, Hanigsen, Germany); Biofuge pico micro centrifuge (Heraeus Instruments, Hanau, Germany); UV-visible spectrophotometer (Shimadzu, model UV-1601 PC, Kyoto, Japan); magnetic stirrer with heater (Yellow Line, MGA HS 7, IKA, Germany); cross-polarized light microscopy (Axioskop, Zeiss, Jena, Germany coupled with a photographic camera, Axiocam, Model ICc3, Jena, Germany); Zetasizer (Malvern instruments, Malvern, UK); digital pH meter (Orion, model 420A, USA); centrifuge with cooling (Hermie Labortechnik GmbH, type Z216MK, Germany); vortex shaker (IKA MS3 Digital, Germany); HPLC (Agilent Technolgies 1200 series, Germany).

\section{Methodology:}

\section{Solubility studies}

An excess amount of $\mathrm{BH}(10 \mathrm{mg})$ was introduced into each of three different capped vials to which $2 \mathrm{mls}$ of each of the investigated oils (IPM, jojoba oil and labr) were added separately. After sealing the capped vials, the mixtures were mechanically shaken for 48 hours using a horizontal mechanical shaker at $25^{\circ} \mathrm{C}$. The mixtures were then allowed to stand for 24 hours for equilibration. Each vial was then centrifuged at 10,000 rpm for 10 minutes using a biofuge pico micro centrifuge, followed by filtration through millipore filter $(0.45 \mu \mathrm{m})$. The amount of $\mathrm{BH}$ was determined by UV-visible spectrophotometer at $239 \mathrm{~nm}$ after proper dilution with isopropyl alcohol (Vyas et al., 2005).

\section{Construction of pseudo-ternary phase diagram}

To explore ME regions; phase diagrams were constructed by water titration method (Chen et al., 2004), two surfactants Labrasol ${ }^{\circledR}$ and $\mathrm{T} 80$ in combination with Transcutol ${ }^{\circledR}$ and PG respectively as cosurfactants were used with any of the selected oils chosen according to the above mentioned solubility study (Kumar et al., 2009). The ratio of oil to the surfactant/cosurfactant mixture (Smix) was varied as follows: 1:9, 2:8, 3:7, 4:6, 5:5, 6:4, 7:3, $8: 2,9: 1(\mathrm{w} / \mathrm{w})$. Surfactants were blent with cosurfactants in a fixed weight ratios $(1: 1$ and $2: 1)$ in order to study the effect of surfactant concentration on the phase region. The oil-Smix mixture was titrated with water dropwise with stirring using a magnetic stirrer with heater at $25^{\circ} \mathrm{C}$ to obtain a transparent ME. After the identification of ME region from the phase diagram, the desired component ratios were selected for ME preparations.

\section{Characterization of unloaded microemulsion formulations}

\subsection{Polarized light microscopy}

To verify the isotropic nature of MEs, samples were examined using cross-polarized light microscopy. A drop of the ME was placed between a cover slip and a glass slide and observed under cross-polarized light (Friberg, 1990; Hathout et al., 2010). 


\subsection{Percent transmittance}

Transparency of the selected MEs was determined by measuring the percentage transmittance through UV-visible spectrophotometer. Percentage transmittance of samples was measured at $633 \mathrm{~nm}$ taking purified water as the blank (Kawtikwar et al., 2009). Triplicate measurements were performed for each sample.

\subsection{Determination of the droplet size}

The particle size of selected MEs was determined by means of dynamic light scattering using a ZetaSizer (El-Laithy, 2003). The scattering intensity data were obtained from pre-filtered $(0.45 \mu \mathrm{m})$ MEs (Delgado-Charro et al., 1997). Samples were loaded into 1 $\mathrm{cm}^{3}$ cuvettes in a thermostated chamber at $25^{\circ} \mathrm{C}$ (Hathout et al., 2010). The measurements were performed after diluting each of the samples 100 -folds with the continuous phase (Rasal et al., 2010). Triplicate measurements were performed for each sample.

\subsection{Determination of the $\mathrm{pH}$}

The $\mathrm{pH}$ measurement was carried out using digital $\mathrm{pH}$ meter. Triplicate measurements were performed for each sample.

\section{Preparation of BH loaded microemulsion}

Buspirone microemulsion was prepared using water titration method. The optimized unloaded ME was chosen to prepare the drug loaded ME formulation in a drug concentration of $1 \%$, (w/w). The formulation was prepared by dissolving the drug in water for the preparation of BHME. The resulting solution was added dropwise to the selected mixture of oil, surfactant and co-surfactant with continuous stirring using a magnetic stirrer with heater at $25^{\circ} \mathrm{C}$.

\section{In-vitro drug release study}

In-vitro release study of ME was carried out by the modified Franz diffusion cell. Dialysis diffusion membrane having molecular weight cut off range of 12000-14000 Da was used where pieces of the membrane were soaked in phosphate buffer, $\mathrm{pH} 6.8$, for 24 hours prior to the experiment. Diffusion cell was filled with phosphate buffer, $\mathrm{pH} 6.8$, and the membrane was then mounted on the cell. The temperature was maintained at $34^{\circ} \mathrm{C}$. After a pre-incubation time of 20 minutes, $\mathrm{ME}$ amount equivalent to $10 \mathrm{mg}$ of $\mathrm{BH}$ was placed in the donor chamber. Aliquots of one $\mathrm{ml}$ samples were withdrawn from the acceptor compartment at time intervals of $5,10,15,30,45,60,120,180$, and subsequently after $360 \mathrm{~min}$. All samples were replaced by equal volumes of fresh phosphate buffer (Rasal et al., 2010). The amount of diffused drug was calculated after measuring the absorbance using a UV-visible spectrophotometer at $238 \mathrm{~nm}$ as shown in Table 1.

Table (1): In-vitro drug release study.

\begin{tabular}{|c|c|c|c|c|c|c|c|}
\hline $\begin{array}{l}\text { Time } \\
\text { (min) }\end{array}$ & Abs* & Slope & D.F* & Conc* & Conc*Aliq* & Conc*D.M* & Cumulative amount \\
\hline 5 & A1 & $\mathrm{S}$ & D1 & $(\mathrm{A} 1 / \mathrm{S}) * \mathrm{D} 1$ & B1 & $\mathrm{C} 1$ & $\mathrm{C} 1$ \\
\hline 10 & A2 & $\mathrm{S}$ & $\mathrm{D} 2$ & $(\mathrm{~A} 2 / \mathrm{S}) * \mathrm{D} 2$ & B2 & $\mathrm{C} 2$ & $\mathrm{C} 2+\mathrm{B} 1$ \\
\hline 15 & A3 & $\mathrm{S}$ & D3 & $(\mathrm{A} 3 / \mathrm{S}) * \mathrm{D} 3$ & B3 & C3 & $\mathrm{C} 3+\mathrm{B} 2+\mathrm{B} 1$ \\
\hline 30 & A4 & $\mathrm{S}$ & D4 & $(\mathrm{A} 4 / \mathrm{S}) * \mathrm{D} 4$ & B4 & $\mathrm{C} 4$ & $\mathrm{C} 4+\mathrm{B} 3+\mathrm{B} 2+\mathrm{B} 1$ \\
\hline 45 & A5 & $\mathrm{S}$ & D5 & $(\mathrm{A} 5 / \mathrm{S}) * \mathrm{D} 5$ & B5 & $\mathrm{C} 5$ & $\mathrm{C} 5+\mathrm{B} 4+\mathrm{B} 3+\mathrm{B} 2+\mathrm{B} 1$ \\
\hline 60 & A6 & $\mathrm{S}$ & D6 & $(\mathrm{A} 6 / \mathrm{S}) * \mathrm{D} 6$ & B6 & C6 & $\mathrm{C} 6+\mathrm{B} 5+\mathrm{B} 4+\mathrm{B} 3+\mathrm{B} 2+\mathrm{B} 1$ \\
\hline 120 & A7 & $\mathrm{S}$ & D7 & $(\mathrm{A} 7 / \mathrm{S}) * \mathrm{D} 7$ & B7 & $\mathrm{C} 7$ & $\mathrm{C} 7+\mathrm{B} 6+\mathrm{B} 5+\mathrm{B} 4+\mathrm{B} 3+\mathrm{B} 2+\mathrm{B} 1$ \\
\hline 180 & A8 & $\mathrm{S}$ & D8 & $(\mathrm{A} 8 / \mathrm{S})^{*} \mathrm{D} 8$ & $\mathrm{~B} 8$ & $\mathrm{C} 8$ & $\mathrm{C} 8+\mathrm{B} 7+\mathrm{B} 6+\mathrm{B} 5+\mathrm{B} 4+\mathrm{B} 3+\mathrm{B} 2+\mathrm{B} 1$ \\
\hline 360 & A9 & $\mathrm{S}$ & D9 & $(\mathrm{A} 9 / \mathrm{S}) * \mathrm{D} 9$ & B9 & C9 & $\mathrm{C} 9+\mathrm{B} 8+\mathrm{B} 7+\mathrm{B} 6+\mathrm{B} 5+\mathrm{B} 4+\mathrm{B} 3+\mathrm{B} 2+\mathrm{B} 1$ \\
\hline
\end{tabular}

Abs: absorbance, D.F: dilution factor, Conc: concentration, Aliq: Aliquots of samples were withdrawn from the acceptor compartment at time intervals of 5, 10, 15, 30, 45, 60, 120, 180, and subsequently after $360 \mathrm{~min}$, D.M: volume of dissolution medium.

Where, cumulative \% of diffused drug $=($ Sum $/ \mathrm{B}) \cdot 100$

B: amount of drug placed in donor chamber. 


\section{Pharmacokinetic studies for buspirone microemulsion}

The pharmacokinetic studies of $\mathrm{BH}$ were determined for the intranasal delivery of BHME, the results were compared to those obtained from I.V delivery of BH solution (BHS). BHS for I.V delivery was prepared as follow:

BH $(10 \mathrm{mg})$ was added to $25 \mathrm{ml}$ of normal saline $(0.9 \% \mathrm{NaCl})$ and with continuous stirring. Final concentration was $0.4 \mathrm{mg} / \mathrm{ml}$.

\subsection{Animal modeling and drug administration}

For all animal studies, the experimental procedures conformed to the ethical principles (Habashy et al., 2005) where108 Wister Albino rats (aged 4-5 months) and weighing $200 \pm$ $20 \mathrm{~g}$ were selected for the study. The animals were randomly divided into 2 groups, each consisting of 54 rats; Group I received IN BHME, and group II received IV BHS. In each group, six rats, per time point, viz., 5, 10, 15, 30, 45, 60, 120, 180 and 360 min were used. Aliquots of $10 \mu \mathrm{l}$ of BHME containing $100 \mu \mathrm{g}$ of $\mathrm{BH}$ (equivalent to $1 \mu \mathrm{g} / \mathrm{g}$ ) were instilled in each of the two nostrils. The conscious rats were held from the back in slanted position during the intranasal administration of the formulation, and the BHME was administered in the openings of the nostrils by means of a micropipette attached with low density polyethylene tube having $0.1 \mathrm{~mm}$ internal diameter at the delivery site. For comparison, $0.5 \mathrm{ml}$ of a 0.4 $\mu \mathrm{g} / \mu \mathrm{l}$ of $\mathrm{BH}$ in normal saline was injected through the tail vein of the rats (group II).

\subsection{Sample preparation for analysis}

\subsubsection{Plasma Treatment}

Blood samples were collected into heparinized tubes. Following centrifugation by using cooling centrifuge at $4000 \mathrm{rpm}$ for $10 \mathrm{~min}$, the resultant plasma was separated and then frozen immediately at $-80^{\circ} \mathrm{C}$ until assayed. $500 \mu \mathrm{l}$ of each of the plasma samples was mixed with $100 \mu \mathrm{l}$ of DILT solution $(1000 \mathrm{ng} / \mathrm{ml})$, acting as the internal standard (IS). One $\mathrm{ml}$ of acetonitrile was finally added. The mixture was then vortex-mixed for $30 \mathrm{sec}$ and subsequently centrifuged at $6000 \mathrm{rpm}$ for $15 \mathrm{~min}$. The supernatant was analyzed for $\mathrm{BH}$ content using HPLC.

\subsubsection{Chromatographic conditions}

The HPLC system consisted of an LC-G 1311A solvent delivery pump equipped with a 20- $\mu 1$ loop and rheodyne sample injector and G1315D diode array detector. The analytical column used was Agilent TC- $_{18}$ column $(250 \mathrm{~mm} \times 4.6 \mathrm{~mm}$ I.D, particle size $5 \mu \mathrm{m})$ at a temperature of $30^{\circ} \mathrm{C}$. The mobile phase was acetonitrile and potassium phosphate buffer $(10 \mathrm{mM}) 35: 65 \mathrm{v} / \mathrm{v}$ at $\mathrm{pH}$ adjusted to 4.6 with few drops of ortho phosporic acid. The eluent was monitored at $235 \mathrm{~nm}$, at a flow rate of $1 \mathrm{~mL} / \mathrm{min}$ and the injection volume was $50 \mu 1$.

\subsection{Pharmacokinetic analysis}

The pharmacokinetic parameters of each formulation were calculated using the WinNonlin ${ }^{\circledR}$ program (Version 2, Pharsight Co., Mountainview, CA, USA). The absolute bioavailability following IN administration of $\mathrm{BH}$ was estimated using the following equation:

$$
\left[A U C_{0-360 \min }(I N) / A U C_{0-360 \min }(I V)\right] \times 100
$$




\section{Data analysis}

All the experiments in the study were performed at least three times and the data were expressed as the mean \pm standard deviation (S.D.). A two-tailed unpaired Student's t-test was performed at $\mathrm{p}<0.05$.

\section{RESULTS AND DISCUSION}

\section{Solubility study}

In order to find appropriate oils which can be used for the ME, the solubility of $\mathrm{BH}$ was measured in various oils. Solubility study shows that, a slightly higher BH was dissolved in Labr $(3.65 \pm 0.03)$ compared to jojoba oil $(3.31 \pm 0.04)$. This might probably be due to the higher polarity of the medium chain triglyceride as shown in Figure 1 which therefore possesses higher solubilizing capacity for the polar $\mathrm{BH}$ compared to jojoba oil which is composed of a mixture of naturally occuring long chained linear esters as shown in Figure 2. Surprisingly and irrespective of this rule, the long chain triglyceride, IPM as shown in Figure 3 , showed the highest solubilizing capacity $(4.38 \pm 0.01)$ compared to the two other oils. This result came in accordance with previous studies which demonstrated the ability of IPM to solubilize a variety of drugs with different nature, however, the mechanism is still poorly understood (Baroli et al., 2000; Peltola et al., 2003; Djordjevic et al., 2004).

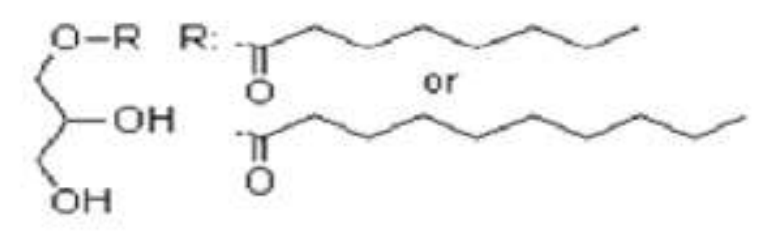

Fig. (1): Chemical structure of labrafac lipophile WL 1349.

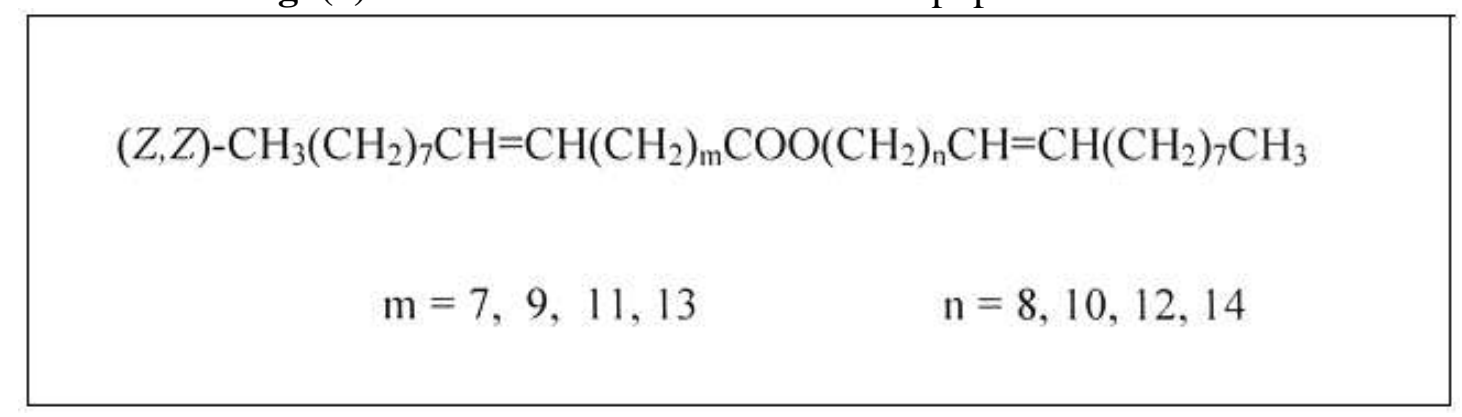

Fig. (2): Chemical structure of jojoba oil.

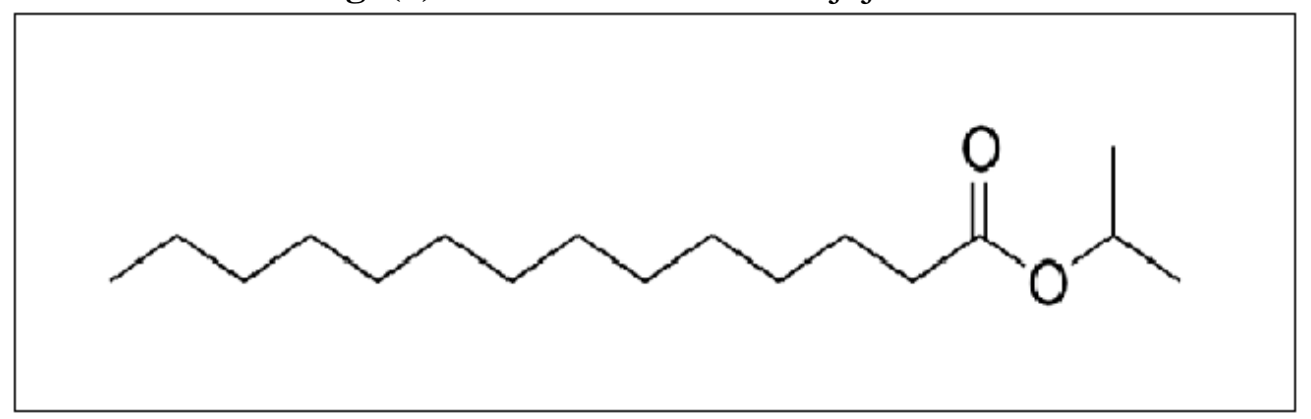

Fig. (3): Chemical structure of isopropyl myristate. 


\section{Phase behavior}

The pseudo-ternary phase diagram of both surfactant/cosurfactant systems (Labrasol ${ }^{\circledR} /$ Transcutol $^{\circledR}$ and T80/PG) at two surfactant/cosurfactant weight ratios $(1: 1$ and 2:1) are presented in Figures (4-7). The ME area is presented in the phase diagrams as shaded region. The rest of the region on the phase diagram represents the turbid conventional emulsions based on visual inspection. The phase diagrams reveal that the existence of the ME area becomes enlarged in case of T80 compared to Labrasol ${ }^{\circledR}$. This could be attributed to the effect of the hydrocarbon chain length of the oils and surfactants. Labrasol ${ }^{\circledR}$ has shorter hydrocarbon chain than T80 and showed smaller ME area (Trotta, 1999). The influence of relative surfactant:cosurfactant concentrations on the ME isotropic region can be evidently seen from phase diagrams. In both systems the ME region increased in size with the higher surfactant concentration. This increase was toward the oil-water axis, indicating that by increasing the T80 or Labrasol ${ }^{\circledR}$ concentration, the maximum amount of water and oil that could be solubilized into the ME increased.

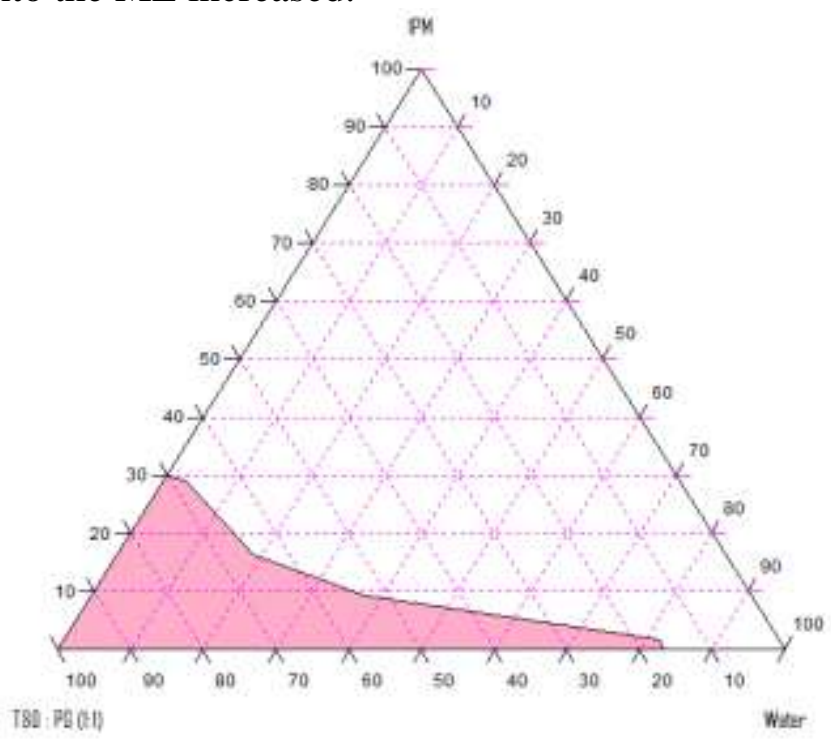

Fig. (4): Pseudo-ternary phase diagram of the microemulsion containing IPM / T80 / PG / Water system where the mixing ratio of T80: PG is $1: 1$.

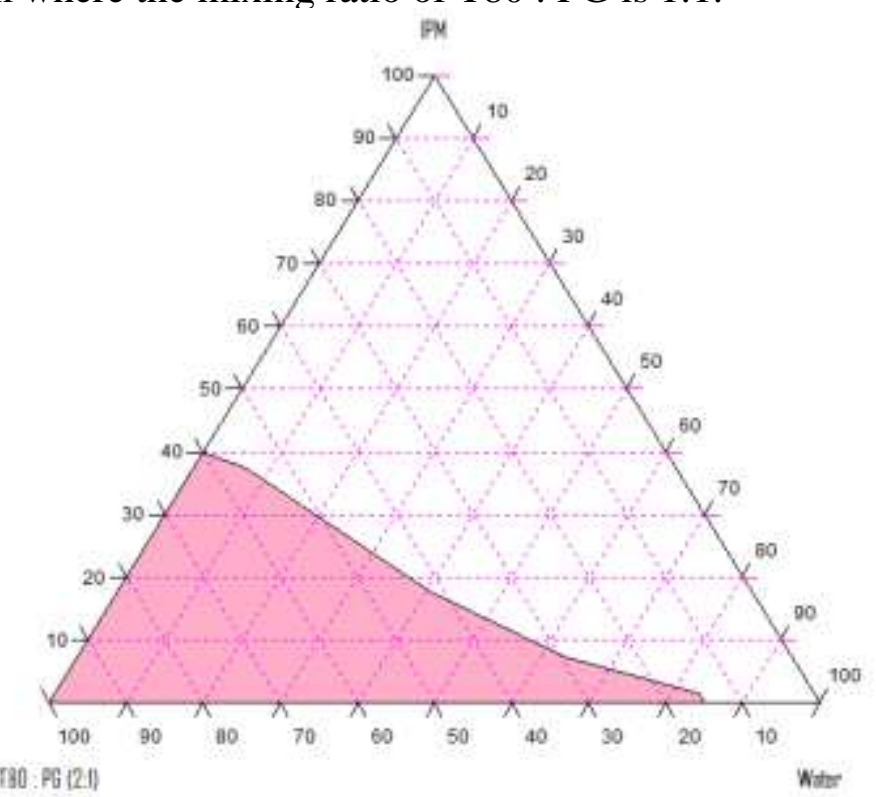

Fig. (5): Pseudo-ternary phase diagram of the microemulsion containing IPM / T80 / PG / Water system where the mixing ratio of $\mathrm{T} 80: \mathrm{PG}$ is $2: 1$. 


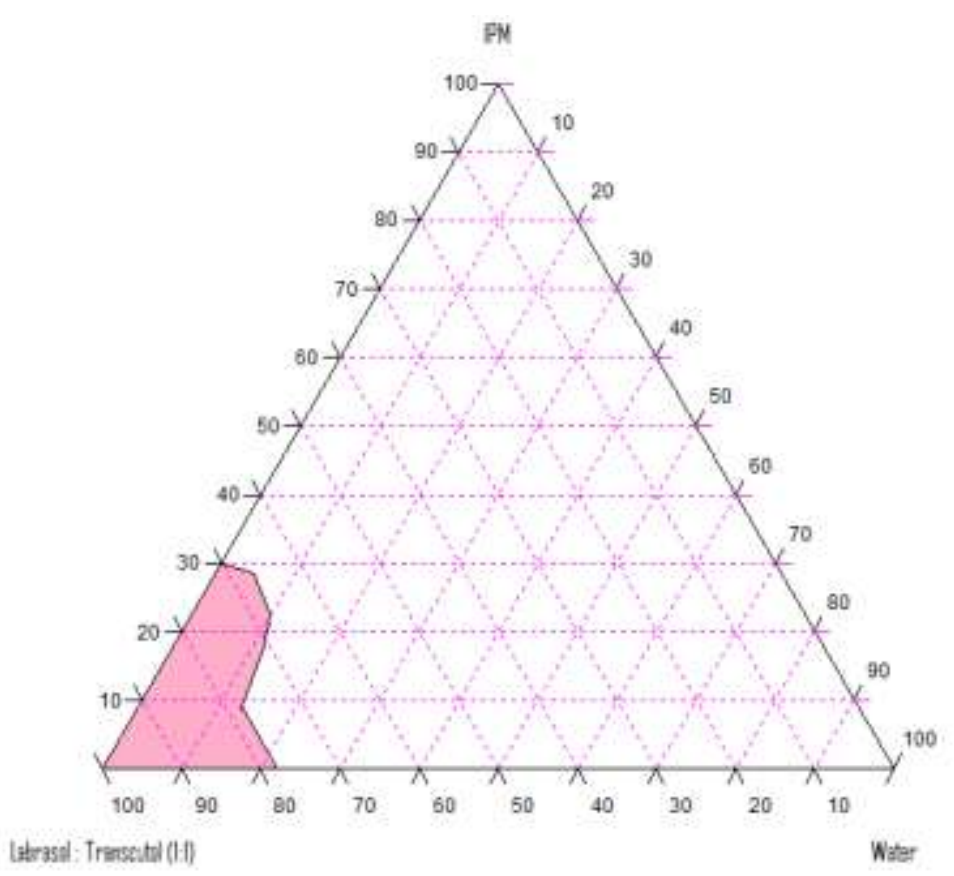

Fig. (6): Pseudo-ternary phase diagram of the microemulsion containing IPM / Labrasol / Transcutol / Water system where the mixing ratio of Labrasol : Transcutol is 1:1.

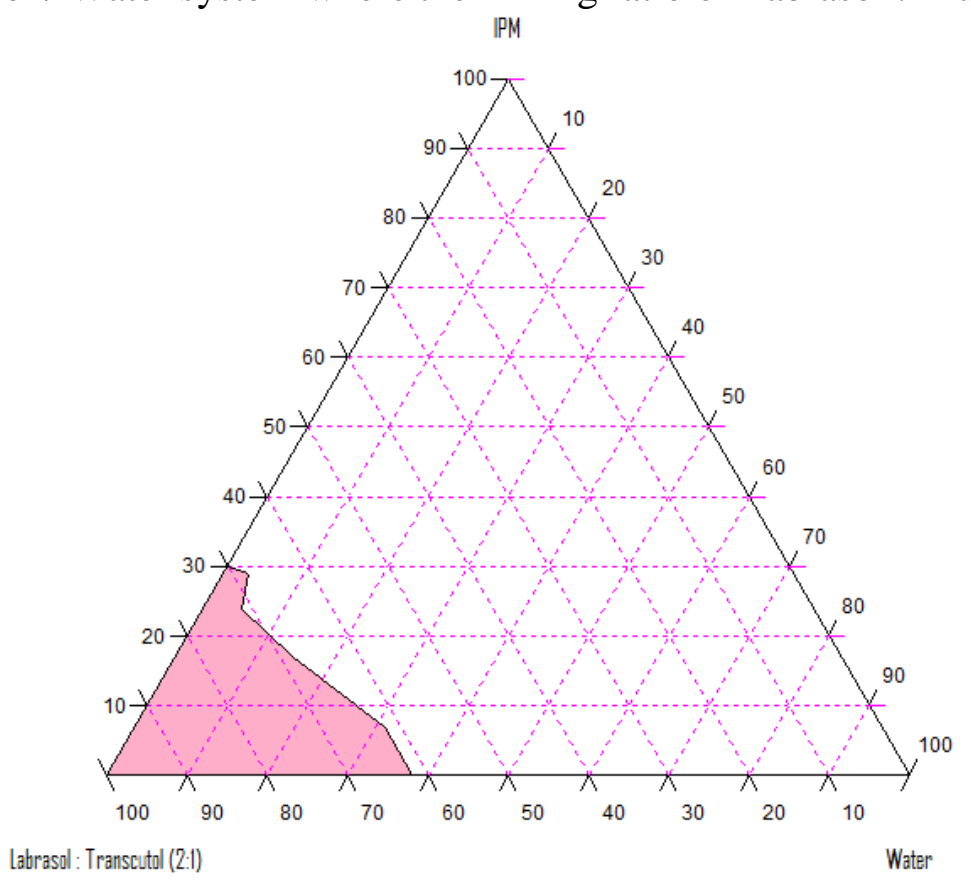

Fig. (7): Pseudo-ternary phase diagram of the microemulsion containing IPM / Labrasol / Transcutol / Water system where the mixing ratio of Labrasol : Transcutol is (a) 1:1, (b) 2:1.

A successful pharmaceutical ME system should not only be stable and transparent, but should also be of relatively low surfactant content and capable of carrying a large amount of drug (Kamila et al., 2009). Oil-in-water (O/W) type of ME was suitable for IN delivery as the nasal secretion was aqueous in nature (Rasal et al., 2010). From the phase diagrams, the ME system IPM / T80 / PG / water with the ratio surfactant:cosurfactant equal 2:1 had sufficiently large ME domain was chosen to prepare four formulations, names; ME A, ME B, ME C, and ME D as shown in Table 2. These ME formulations were prepared i.e. ME A to ME D in varying concentration of surfactants and water, oil concentration was fixed to $5 \%$. 
Table (2): Composition of the prepared microemulsions.

\begin{tabular}{|l|l|l|l|l|}
\hline $\begin{array}{c}\text { Microemulsion } \\
\text { systems }\end{array}$ & \multicolumn{1}{|c|}{ Oily phase } & Surfactant & \multicolumn{1}{|c|}{\begin{tabular}{c} 
Cosurfactant \\
\cline { 2 - 5 }
\end{tabular}} & $\begin{array}{c}\text { Aqueous } \\
(\%, w / w) \\
\text { phase }\end{array}$ \\
\hline$A$ & 5 & $\begin{array}{c}\text { Tween80 } \\
(\%, w / w)\end{array}$ & $\begin{array}{c}\text { Propylene glycol } \\
(\%, w / w)\end{array}$ & $\begin{array}{c}\text { Purified water } \\
(\%, w / w)\end{array}$ \\
\hline$B$ & 5 & 30 & 15 & 50 \\
\hline$C$ & 5 & 36 & 18 & 41 \\
\hline$D$ & 5 & 40 & 20 & 35 \\
\hline
\end{tabular}

\section{Characterization of unloaded microemulsion formlations}

\subsection{Polarized light microscopy}

Isotropic material, such as a ME, in contrast to anisotropic liquid crystals, will not interfere with the polarized light (Friberg, 1990) and the field of view remains dark. In this context, all the investigated ME fields remained dark under the polarized microscope.

\subsection{Percent transmittance}

The percentage transmittance for the selected MEs ranged from $99.23 \pm 0.18 \%$ to $99.52 \pm 0.43 \%$ as shown in Table (3), indicating transparency and stability of the selected microemulsions (Formariz et al., 2006).

\subsection{Particle size}

All formulae showed a fairly unimodal particle size distribution as shown in Figures (8-11). Data presented in Table (3) show that the lowest particle size value was achieved with ME D containing the highest amount of surfactants and the highest particle size value was achieved from ME A containing the lowest amount of surfactants. As previously reported, the addition of surfactant to ME system causes the interfacial film to condense leading to a reduction in particle size (Kale and Allen, 1989).

\section{4. $\mathrm{pH}$}

The $\mathrm{pH}$ range of the selected MEs was $6.2 \pm 0.05$ to $6.4 \pm 0.03$ as shown in Table 3. For intranasal application, the ideal $\mathrm{pH}$ of any suggested formulation should be in the range of 4.5 - 6.5 (Arora et al., 2002). The main disadvantage of microemulsions in pharmaceutical application is that they usually contain a large amount of surfactants which can cause irritation in the nasal mucosa. In order to select a microemulsion system pharmaceutically acceptable; it is necessary to select such systems which contains the least amount of surfactants to prevent or reduce irritation as possible.

Table (3): Physicochemical parameters of selected microemulsion formulations.

\begin{tabular}{|l|l|l|l|l|}
\hline \multirow{2}{*}{ Parameters* } & \multicolumn{4}{c|}{ Microemulsion type } \\
\cline { 2 - 5 } & \multicolumn{1}{|c|}{$A$} & \multicolumn{1}{c|}{ B } & \multicolumn{1}{c|}{$C$} & D \\
\hline \% Transmittance & $99.52 \pm 0.43 \%$ & $99.32 \pm 0.29 \%$ & $99.28 \pm 0.15 \%$ & $99.23 \pm 0.18 \%$ \\
\hline Particle size (nm) & $35.1 \pm 0.5$ & $30.2 \pm 0.5$ & $28.6 \pm 0.4$ & $25.7 \pm 0.2$ \\
& & & & \\
\hline$p H$ & $6.40 \pm 0.03$ & $6.35 \pm 0.07$ & $6.30 \pm 0.06$ & $6.20 \pm 0.05$ \\
\hline
\end{tabular}

$*$ Values are mean \pm SD., $\mathrm{n}=3$. 


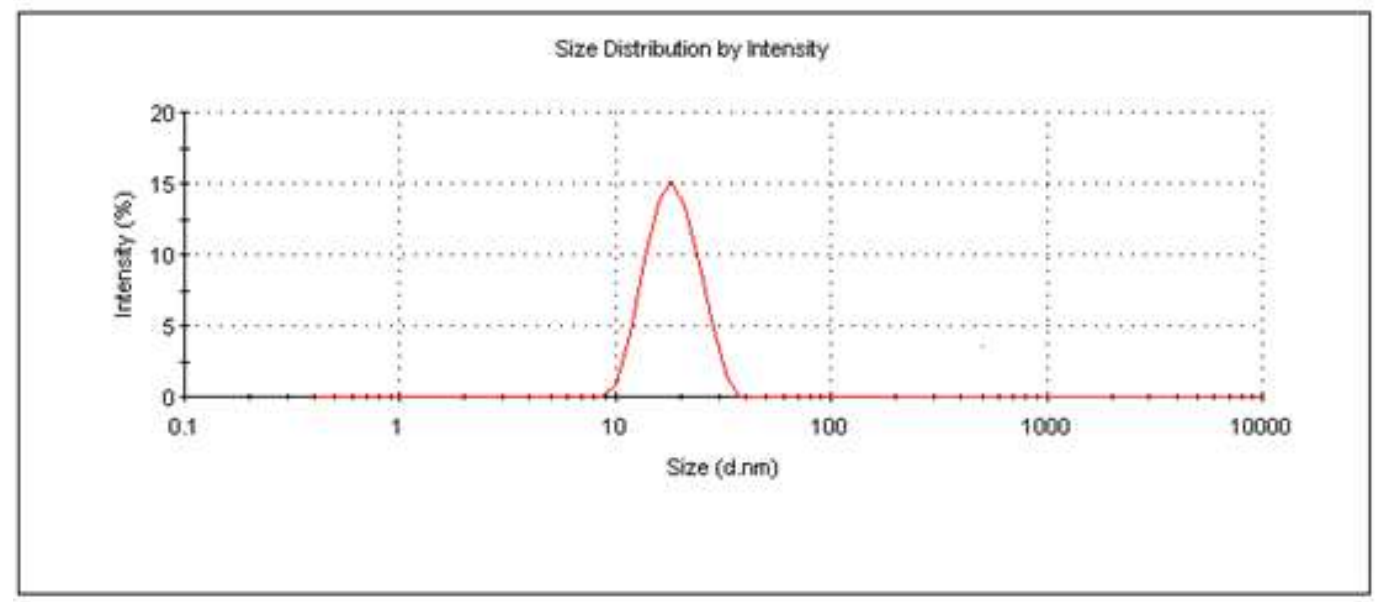

Fig. (8): Particle size distribution of microemulsion A [IPM / Tween80 / Propylene glycol / water (5: 30: 15: 50) $(\% \mathrm{w} / \mathrm{w})]$.

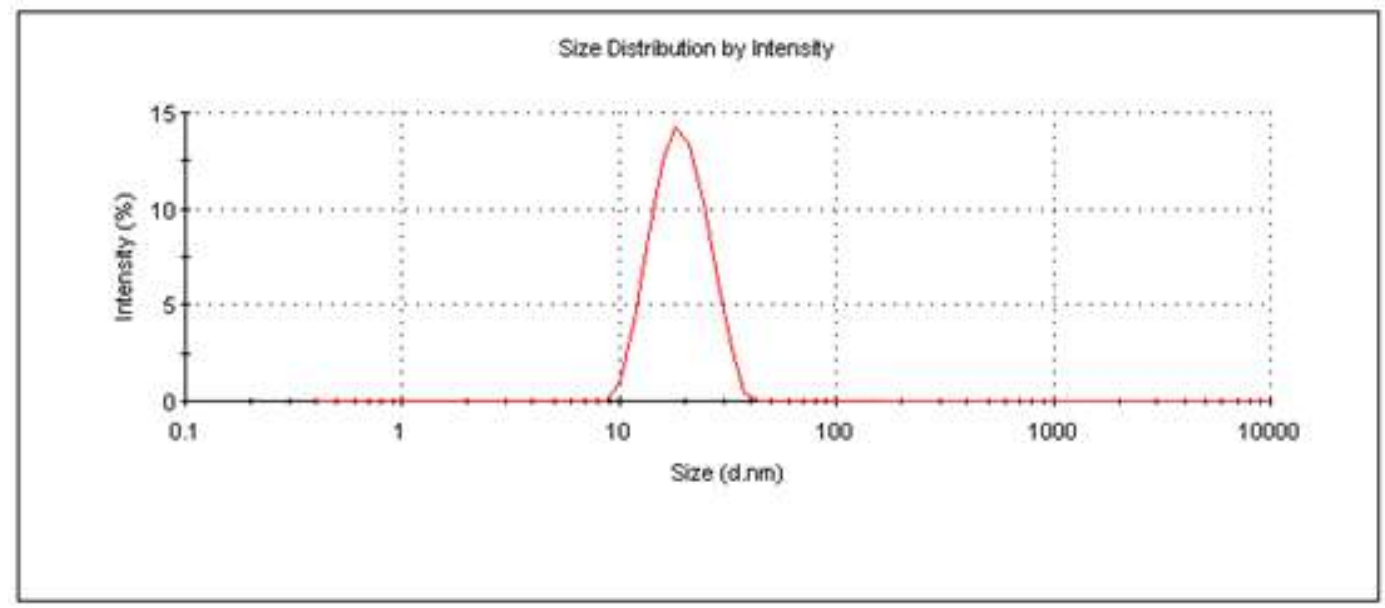

Fig. (9): Particle size distribution of microemulsion B [IPM / Tween80 / Propylene glycol / water (5: 44: 22.5: 27.5) $(\% \mathrm{w} / \mathrm{w})]$.

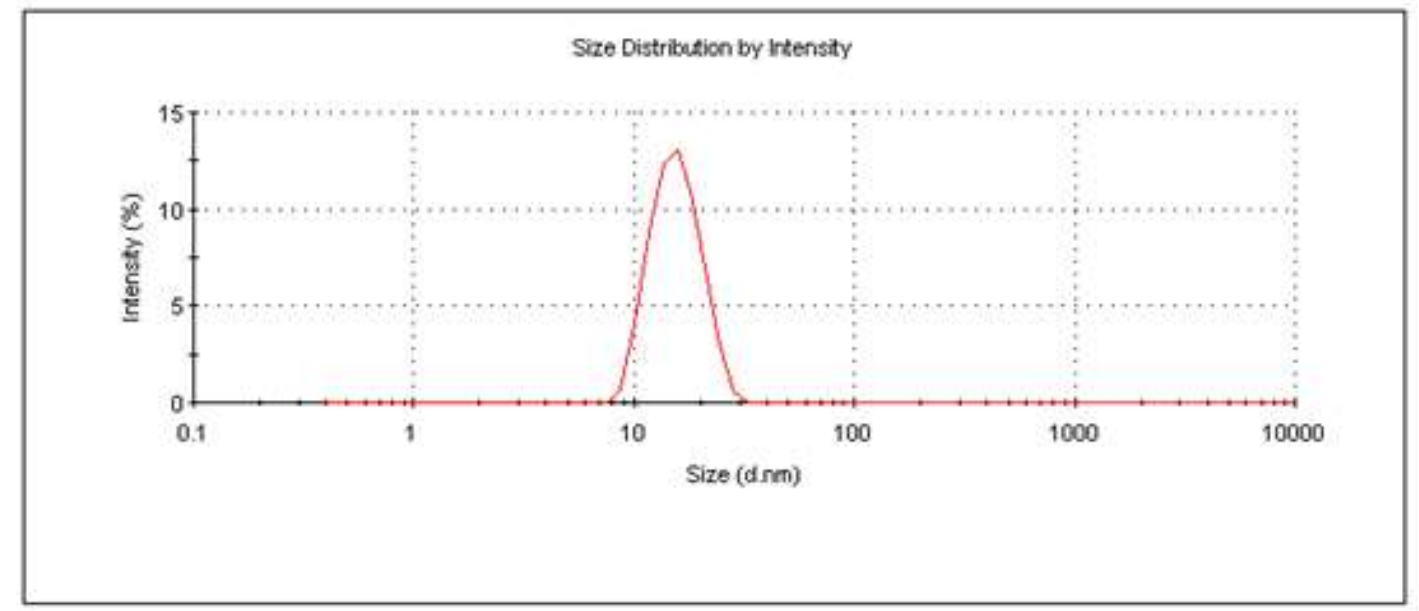

Fig. (10): Particle size distribution of microemulsion C [IPM / Tween 80 / Propylene glycol / water (5: 36: 18: 41) $(\% \mathrm{w} / \mathrm{w})]$. 


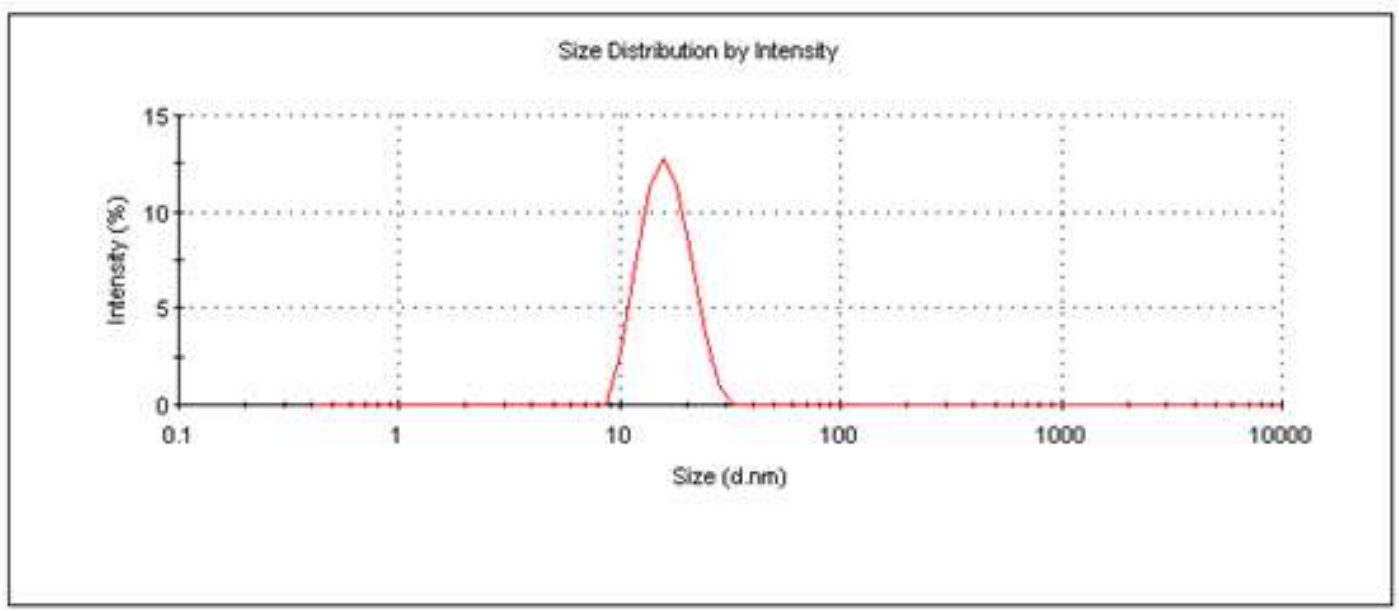

Fig. (11): Particle size distribution of microemulsion D [IPM / Tween80 / Propylene glycol / water (5: 40: 20:35) $(\% \mathrm{w} / \mathrm{w})]$.

From the above mentioned results, all prepared MEs showed properties promising for nasal delivery. However, microemulsion A composed of IPM (5\%) / Tween80 (30\%) / Propylene glycol (15\%) / water (50\%) with the ratio surfactant:cosurfactant 2:1, contains the least amount of surfactant needed for maximum water solubilization and was therefore selected for preparation of BHME formulation.

\section{In-vitro drug release study}

As shown in Figure 12 and Table 4, buspirone solution showed 100\% cumulative drug release after $2 \mathrm{~h}$. The percentage drug release was $100 \%$ after $3 \mathrm{~h}$ in ME. The inhibition in release of $\mathrm{BH}$ by the $\mathrm{ME}$ could be due to the high viscosity of microemulsion compared to solution. However, the release rate of the formulation is considered to be decreased with the increase in the viscosity of the formulation, resulting in a delay of the drug's approach to the dissolution medium (Furubayashi et al., 2007).

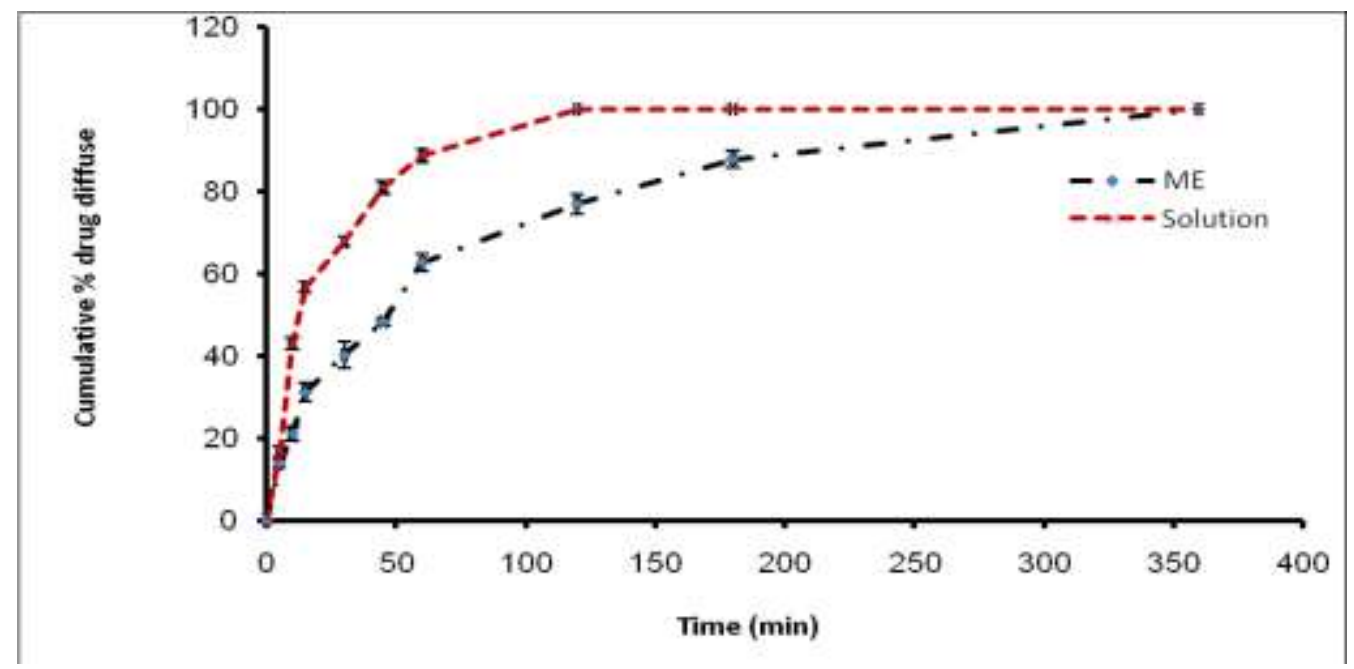

Fig. (12): In-vitro drug release profile of buspirone $\mathrm{HCl}$ microemulsions. 
Table (4): In-vitro release of buspirone hydrochloride from solution and microemulsion formulations.

\begin{tabular}{|l|l|l|}
\hline \multirow{2}{*}{ Time $(\mathrm{min})$} & \multicolumn{2}{|l|}{ \% Drug released (mean \pm S.D.) from: } \\
\cline { 2 - 3 } & Solution & Microemulsion \\
\hline 5 & $16.80 \pm 1.10$ & $13.83 \pm 0.89$ \\
\hline 10 & $42.97 \pm 1.40$ & $21.05 \pm 1.72$ \\
\hline 15 & $56.75 \pm 1.29$ & $31.22 \pm 2.36$ \\
\hline 30 & $67.75 \pm 1.11$ & $40.25 \pm 3.17$ \\
\hline 45 & $80.94 \pm 1.74$ & $48.31 \pm 0.79$ \\
\hline 60 & $88.71 \pm 1.49$ & $62.64 \pm 2.13$ \\
\hline 120 & 100 & $77.01 \pm 2.37$ \\
\hline 180 & 100 & $87.85 \pm 2.12$ \\
\hline 360 & 100 & 100 \\
\hline
\end{tabular}

\section{Pharmacokinetic studies for buspirone microemulsion}

The retention time of $\mathrm{BH}$ in plasma was 6.6 - $6.9 \mathrm{~min}$, and for the IS, it is $10.3-10.5$ with a total run time of less than 15 min as shown in Figure 13. The analytical process of BH and IS were resolved with good symmetry. No endogenous interfering peaks were observed in individual blank serum at the retention times of BH and IS, thereby confirming the specificity of the analytical method. The standard plots obtained for plasma samples were linear in the concentration range $1-800 \mathrm{ng} / \mathrm{ml}$ as shown in Figure 14. The correlation coefficient-values $\left(\mathrm{R}^{2}\right)$ determined was 0.9987 for rat plasma. The percentage recovery-values were in the range 92.289 - 98.981 for the BH-spiked plasma as shown in Table 5. The recovery of BH using the described procedure was consistent and efficient. The inter-day accuracy and precision for rat plasma samples were determined on three different days, the percentage coefficient of variance (C.V) was determined by the analysis of three replicates of samples at three different concentrations. The inter-day and intra-day precisions of the samples were satisfactory with coefficient of variation (C.V) less than $15 \%$ as shown in Table 6 and Table 7 . The limit of quantitation (LOQ) of the method was found to be $1 \mathrm{ng} / \mathrm{ml}$ for $\mathrm{BH}$ in rat plasma with C.V less than $20 \%$ and an accuracy of 85 to $110 \%$. The limit of detection (LOD) was determined to be $0.5 \mathrm{ng} / \mathrm{ml}$ based on signal-to-noise $(\mathrm{s} / \mathrm{n})$ ratio of $3: 1$.

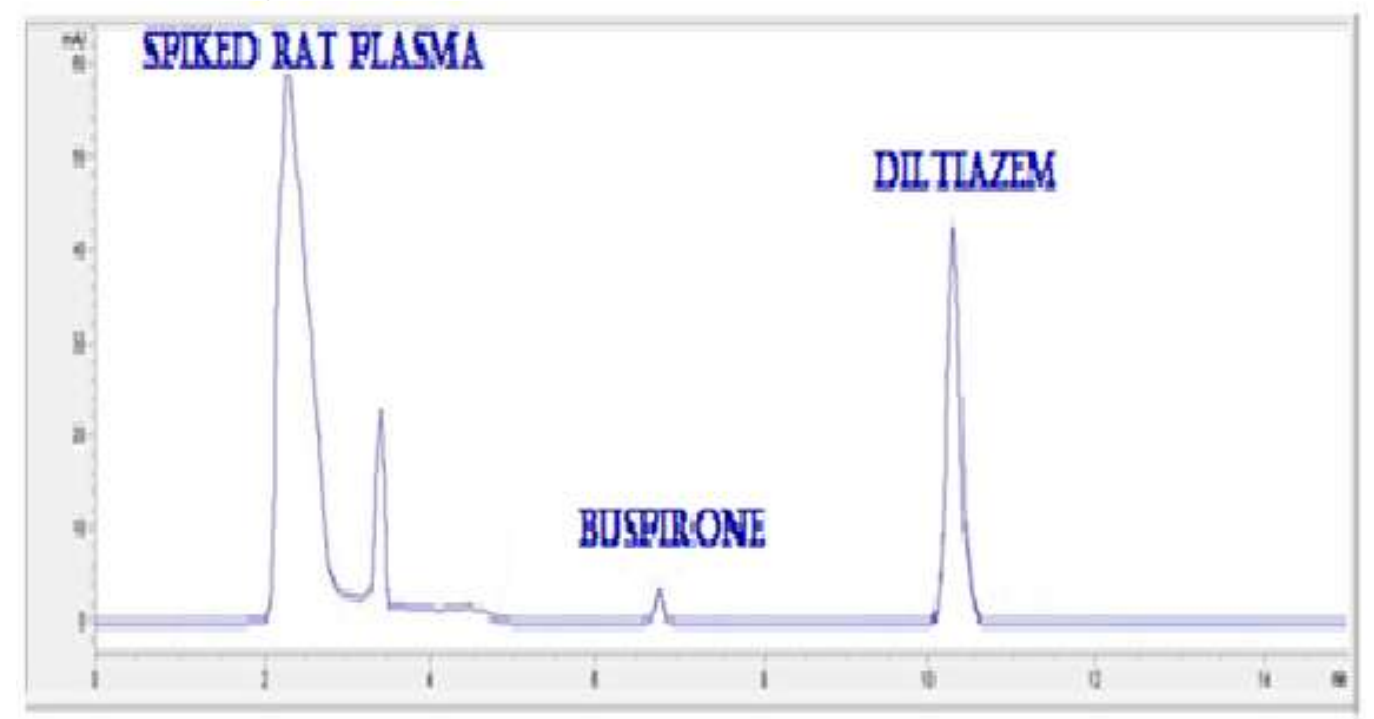

Fig. (13): Representative chromatogram of buspirone $\mathrm{HCl}$ and diltiazem in rat plasma. 


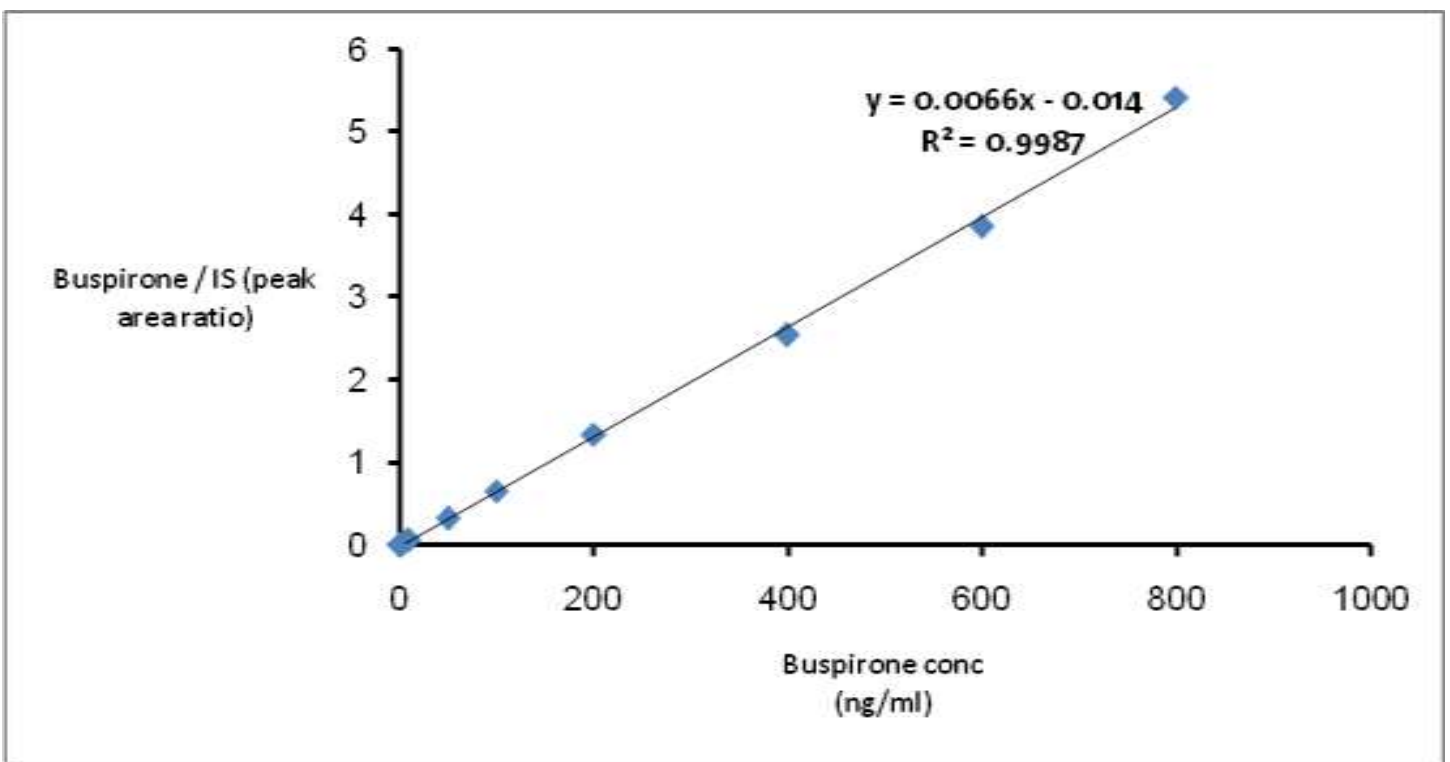

Fig. (14): Calibration curve for buspirone $\mathrm{HCl}$ in rat plasma.

Table (5): Recovery data for buspirone from spiked rat plasma.

\begin{tabular}{|c|c|c|c|c|c|c|c|}
\hline \multirow{2}{*}{$\begin{array}{l}\text { Spiked } \\
\text { conc } \\
(n g / m l)\end{array}$} & \multicolumn{3}{|c|}{ Measured conc $(\mathrm{ng} / \mathrm{ml})$} & \multirow{2}{*}{$\begin{array}{l}\text { Mean conc } \\
\quad(\mathrm{ng} / \mathrm{ml})\end{array}$} & \multirow{2}{*}{$\begin{array}{c}\text { Recovery } \\
(\%)\end{array}$} & \multirow[t]{2}{*}{$S D$} & \multirow{2}{*}{$\begin{array}{l}C V \\
(\%)\end{array}$} \\
\hline & $A$ & $B$ & $C$ & & & & \\
\hline 1 & 0.9676 & 0.9458 & 0.9185 & 0.94395 & 94.395 & 0.0246 & 2.6084 \\
\hline 5 & 4.9505 & 4.5085 & 4.4110 & 4.6233 & 92.466 & 0.2874 & 6.2184 \\
\hline 10 & 9.5650 & 9.0630 & 9.6580 & 9.4286 & 94.286 & 0.3200 & 3.3946 \\
\hline 50 & 49.476 & 44.980 & 48.515 & 48.430 & 96.860 & 2.3676 & 4.8887 \\
\hline 100 & 95.760 & 98.250 & 97.500 & 97.170 & 97.170 & 1.2773 & 1.3145 \\
\hline 200 & 185.00 & 197.35 & 188.62 & 190.323 & 95.161 & 6.3487 & 3.3357 \\
\hline 400 & 392.8 & 388.15 & 378.9 & 386.617 & 96.654 & 7.0757 & 1.8301 \\
\hline 600 & 571.9 & 568.5 & 589 & 576.467 & 96.078 & 10.986 & 1.906 \\
\hline 800 & 793.9 & 795.4 & 785 & 791.433 & 98.929 & 5.6217 & 0.7103 \\
\hline
\end{tabular}


Table (6): Intra-day precision and accuracy data for assay of buspirone $\mathrm{HCl}$ in rat plasma $(\mathrm{n}=3)$.

\begin{tabular}{|c|c|c|c|c|c|c|}
\hline \multirow{2}{*}{$\begin{array}{c}\text { Spiked conc } \\
(\mathrm{ng} / \mathrm{ml})\end{array}$} & \multicolumn{3}{|c|}{ Measured conc (ng/ml) } & \multirow{2}{*}{$\begin{array}{c}\text { Mean conc } \\
(\text { ng/ml })\end{array}$} & \multirow[t]{2}{*}{$S D$} & \multirow{2}{*}{ CV\% } \\
\hline & $A$ & $B$ & $C$ & & & \\
\hline 2.5 & 2.483 & 2.486 & 2.278 & 2.416 & 0.1192 & 4.936 \\
\hline 250 & 240.84 & 248.7 & 244.12 & 244.553 & 3.9479 & 1.614 \\
\hline 650 & 629.02 & 640.1 & 641.9 & 637.007 & 6.9749 & 1.095 \\
\hline
\end{tabular}

Table (7): Inter-day precision and accuracy data for assay of buspirone $\mathrm{HCl}$ in rat plasma $(\mathrm{n}=3)$.

\begin{tabular}{|c|c|c|c|c|c|c|}
\hline \multirow{2}{*}{$\begin{array}{c}\text { Spiked conc } \\
(\mathrm{ng} / \mathrm{ml})\end{array}$} & \multicolumn{3}{|c|}{ Measured conc $(\mathrm{ng} / \mathrm{ml})$} & \multirow{2}{*}{$\begin{array}{c}\text { Mean conc } \\
(n g / m l)\end{array}$} & \multirow[t]{2}{*}{$S D$} & \multirow[t]{2}{*}{ CV\% } \\
\hline & $A$ & $B$ & $C$ & & & \\
\hline 2.5 & 2.467 & 2.475 & 2.147 & 2.363 & 0.1871 & 7.918 \\
\hline 250 & 242.81 & 245.67 & 235.36 & 241.28 & 5.3226 & 2.206 \\
\hline 650 & 620.11 & 637.07 & 634.41 & 630.53 & 9.1215 & 1.447 \\
\hline
\end{tabular}

The mean plasma drug concentration-time profiles after administration of the IV drug solution as well as the IN BHME are illustrated in Figure 15. The corresponding bioavailability and pharmacokinetic parameters in plasma are shown in Table 8 . It is evident that (as expected) drug concentration in rat plasma reached its maximum value $\left(\mathrm{C}_{\max }=\right.$ $668.07 \pm 27.85 \mathrm{ng} / \mathrm{ml}$ ) following administration of the IV drug solution at first $5 \mathrm{~min}$, whereas it reached its maximum value $\left(\mathrm{C}_{\max }=206.69 \pm 13.95 \mathrm{ng} / \mathrm{ml}\right)$ following administration of the $\mathrm{IN}$ drug microemulsion at $10 \mathrm{~min}$. Moreover, the $\mathrm{AUC}_{0-360 \mathrm{~min}}$ values were 51606.27 \pm 1617.20 and $8167.51 \pm 532.11 \mathrm{ng} / \mathrm{ml} . \mathrm{min}$ for the IV drug solution and IN drug ME, respectively.

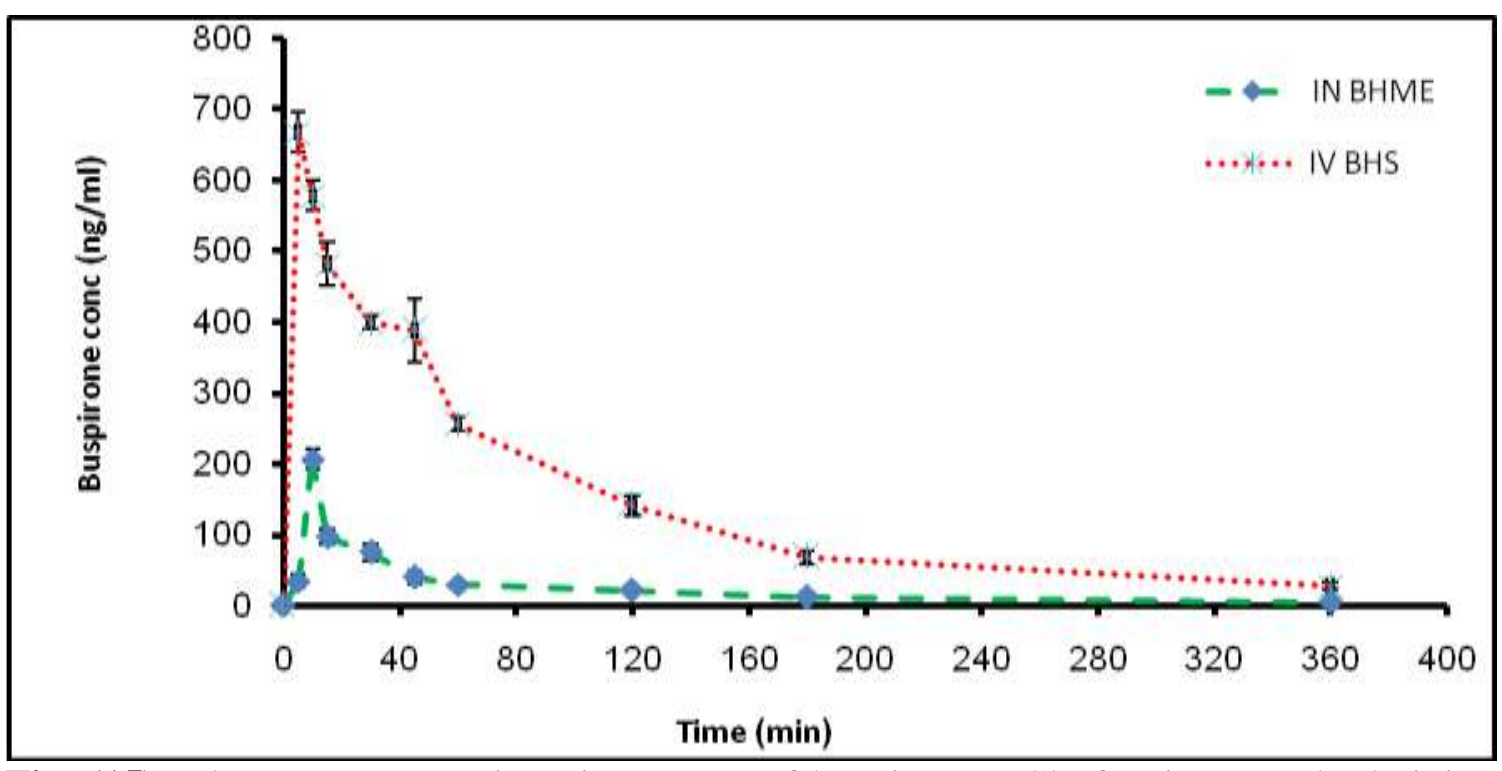

Fig. (15): Plasma concentration-time curve of buspirone $\mathrm{HCl}$ after intranasal administration of microemulsion and intravenous administration of solution to rats in a dose of 1 $\mathrm{mg} / \mathrm{kg}$ 
Table (8): Pharmacokinetic parameters of Buspirone $\mathrm{HCl}$ after intranasal administration of microemulsion and intravenous administration of solution to rats in a dose of 1 $\mathrm{mg} / \mathrm{kg}$.

\begin{tabular}{|c|c|c|}
\hline \multirow{2}{*}{$\begin{array}{c}\text { Pharmacokinetic } \\
\text { Parameters }\end{array}$} & \multicolumn{2}{|c|}{ Formulations } \\
\hline & $\begin{array}{c}\text { Intranasal buspirone } \\
\text { microemulsion }\end{array}$ & $\begin{array}{c}\text { Intravenous buspirone } \\
\text { solution }\end{array}$ \\
\hline$C_{\max }(n g / m l)$ & $206.69 \pm 13.95$ & $668.07 \pm 27.85$ \\
\hline$t_{\max }(\min )$ & 10 & $<5 \min$ \\
\hline$A U C_{0-360 \min }(n g / m l . m i n)$ & $8167.51 \pm 532.11$ & $51606.27 \pm 1617.20$ \\
\hline Absolute bioavailability (\%) & $15.83 \pm 1.03$ & - \\
\hline$t_{1 / 2}(\min )$ & $110.46 \pm 13.68$ & $95.28 \pm 18.57$ \\
\hline $\operatorname{MRT}(\min )$ & $123.14 \pm 10.40$ & $113.05 \pm 13.95$ \\
\hline
\end{tabular}

Results of $\mathrm{C}_{\max }$ and $\mathrm{AUC}_{0-360 \min }$ in rat plasma may indicate that there is a correlation between in-vitro release studies and amount of the drug transported to the plasma. In our previous in-vitro release study (Fig 12) have demonstrated a high release of drug in case of solution and slower diffusion of drug in case of microemulsion formulation, whereas the invivo studies (Fig 15) showed low values for $\mathrm{C}_{\max }$ and $\mathrm{AUC}_{0-360}$ for IN $\mathrm{ME}$ and high values for $\mathrm{C}_{\max }$ and $\mathrm{AUC}_{0-360}$ for IV solution.

Concerning the absolute drug bioavailability it is evident that, drug microemulsion formulation administered intranasally increased the bioavailability about four folds $(15.83 \pm 1.03 \%)$ as shown in Table 8 compared to its oral tablets $(\sim 4 \%)$ (Galichet, 2004), which could be attributed to escaping the first-pass metabolism occuring with peroral drug administration.

The $t_{1 / 2}$ of $95.28 \pm 18.57-110.46 \pm 13.68 \mathrm{~min}$ and the mean residence time (MRT) of $113.05 \pm 13.95-123.14 \pm 10.40$ were observed irrespective of the routes of administration and the type of the formulations as shown in Table 8.

\section{CONCLUSION}

Intranasal buspirone $\mathrm{HCl}$ instilled in a microemulsion formula composed of isopropyl myristate $(5 \%)$, Tween $80(30 \%)$, propylene glycol (15\%), and purified water $(50 \%)$, proves safe, viable, and a practically feasible approach for the improvement of the therapeutic effect. Overall, the present study has indicated that the buspirone microemulsion formulations as an efficient as well as efficacious approach for the intranasal delivery of the drug besides being simple and applicable. 


\section{REFERENCES}

Arora, P.; Sharma, S.; Gary, S.S. (2002): Permeability issues in nasal drug delivery. Drug Deliv. Tech, 7, 967-975.

Baroli, B.; Lopez-Quintela, M.A.; Delgado-Charro, M.B.; Fadda, A.M.; Blanco-Mendez, J. (2000): Microemulsions for topical delivery of 8-methoxsalen. J. Controlled Release, 69, 209-218.

Chen, H.; Chang, X.; Weng, T.; Zhao, X.; Gao, Z.; Yang, Y.; Xu, H.; Yang, X. (2004): A study of microemulsion systems for transdermal delivery of triptolide. J. Controlled Release.98, 427- 436.

Delgado-Charro, M.B.; Iglesias-Vilas, G.; Blanco-Mendez, J.; Lopez- Quintela, M.A.; Marty, J.P.; Guy, R.H. (1997): Delivery of a hydrophilic solute through the skin from novel microemulsion systems. Eur. J. Pharm. Biopharm. 43, 37-42.

Djordjevic, L.; Primorac, M.; Stupar, M.; Krajisnik, D. (2004): $\quad$ Characterization $\quad$ of caprylocaproyl macrogloglycerides based microemulsion drug delivery vehicles for an amphiphilic drug. Int. J. Pharm, 271, 11-19.

El-Laithy, H.M. (2003): Preparation and physicochemical characterization of dioctyl sodium sulfosuccinate (aerosol OT) microemulsion for oral drug delivery. AAPS Pharm. Sci. Tech, $4 \quad$ E11.

Formariz, T.P.; Sarmento, V.H.V.; Silva-Junior, A.A.; Scarpa, M.V.; Santilli, $\quad$ C.V.; Oliveira, A.G. (2006): Doxorubicin biocompatible O/W microemulsion stabilized by mixed surfactant containing soya phosphatidylcholine. Colloids Surf. B: Biointerfaces. 51, 54-61.

Friberg, S.E. (1990): Micelles, microemulsions, liquid-crystals, and the structure of stratum-corneum lipids. J. Soc. Cosmet. Chem. 41, 155-171.

Furubayashi, T.; Inoue, D.; Kamaguchi, A.; Higashi, Y.; Sakane, T.; $\quad$ (2007): Influence of formulation viscosity on drug absorption following nasal application in rats. Drug Metabol. Pharmacokinet, 22, 206-211.

Galichet, L.Y. (2004): Clarke's analysis of drugs and poisons in pharmaceuticals, body fluids and postmortem material. $3^{\text {rd }}$ ed, Vol II, Pharmaceutical Press, UK, pp. 726-727.

Habashy, R.R.; Abdel-Naim, A.B.; Khalifa, A.E.; Al-Azizi, M.M. Anti-inflammatory effects of jojoba liquid wax in experimental models. Pharmacol. Res, 51, 95-105.

Hathout, R.M.; Woodman, T.J.; Mansour, S; Mortada, N.D.; Geneidi, A.S.; Guy, R.H. (2010): Microemulsion formulations for the transdermal delivery of testosterone. Eur. J. Pharm. Sci. 40, 188-196.

Jadhav, K.R.; Shaikh, I.M.; Ambade, K.W.; Kadam, V.J. (2006): Applications $\quad$ of microemulsion based drug delivery system, Curr. $\quad$ Drug Delivery. 3, 267273.

Kale, N.J.; Allen, L.V. (1989): Studies of microemulsion using Brij 96 as surfactant and glycerine, ethylene glycol and Propylene glycol as co surfactant. Int. J. Pharm, 57, 87-93. 
Kamila, M.M.; Mondal, N.; Gupta, B.K.; Ghosh, L.K. (2009): $\quad$ Preparation, characterization, and in-vitro evaluation of sunflower oil-Tween80-Glycerolbased microemulsion formulation of a BCS Class-II Drug. Lat. Am. J. Pharm, $28,622-7$.

Kawtikwar, P.S.; Kulkarni, N.P.; Yadav, S.; Sakarkar, D.M. (2009): $\quad$ Formulation $\quad$ and evaluation of an anti-epileptic drug-loaded microemulsion for nose to brain delivery. Asian. J. Pharm. 3, 143- 147.

Kumar, A.; Sharma, P.; Chaturvedi1, A.; Jaiswal1, D.; Bajpail,M.; $\quad$ Choudhary, $\quad$ M.; Yadav, I.K.; Singh, H.P.; Chandra, D.; Jain, D.A. (2009): $\quad$ Formulation development of sertaline hydrochloride microemulsion for intranasal delivery. Int. J. ChemTech. Res. 1, 941-947.

Lin, H.; Gebhardt, M.; Bian, S.; Kwon, K.A.; Shim, C.K.; Chung, S.J.; Kim, D.D. (2007): Enhancing effect of surfactants on fexofenadine $\mathrm{HCl}$ transport across the human nasal epithelial cell monolayer. Int. J. Pharm. 330, 23-31.

Peltola, S.; Saarinen-Savolainen, P.; Kiesvaara, J.; Suhonen, T.M.; $\quad$ Urtti, A. (2003): Microemulsions for topical delivery of estradiol. Int. J. Pharm. 254, 99-107.

Rasal, A.; Mahajan, H.S.; Shaikh, H.T.; Surana, S.J. (2010): $\quad$ Development $\quad$ and characterization of nasal mucoadhesive microemulsion of sumatriptan succinate. Ind. J. Novel Drug Delivery.2, 103-108.

Trotta, M. (1999): Influence of phase transformation on indomethacin release from microemulsions. J. Controlled Release, 99, 399-405.

Vyas, T.K .; Babbar, A.K.; Sharma, R.K.; Misra, A. (2005): Intranasal mucoadhesive microemulsions of zolmitriptan: Preliminary studies on brain-targeting. J. Drug Targeting, 13, 317-324.

Yin, Y.M.; Cui, F.D.; Mu, C.F.; Choi, M.K.; Kim, J.S.; Chung, S.J.; $\quad$ Shim, C.K.; Kim, D.D. (2009): Docetaxel microemulsion for enhanced oral bioavailability: Preparation and in-vitro and in-vivo evaluation. J. Controlled Release. 140, 86-94.

Zhang, Q.; Jiang, X.; Jiang, W.; Lu, W.; Su, L.; Shi, Z. (2004): Preparation of nimodipine loaded microemulsion for intranasal delivery and evaluation on the targeting efficiency to the brain. Int. J. Pharm. 275, 85-96. 


\title{
تحسين التوافر الحيوى لهيدروكلوريد البسبيرون باستعمال نظم إيتاء دوائية داخل الانف
}

\author{
حمزه نمر بشارة - ريحاب عثمان أحمد - سمر منصور هليل - عبد الحميد عبد الله الثشامي \\ قسم الصيدلانيات و الصيدلة الصناعية - كلية الصيدلة - جامعة عين شمس
}

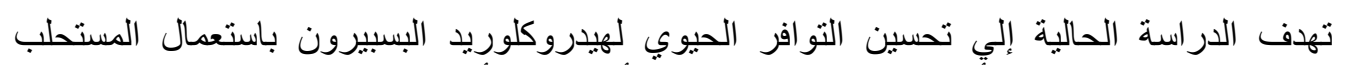

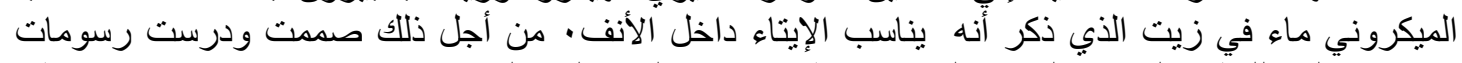

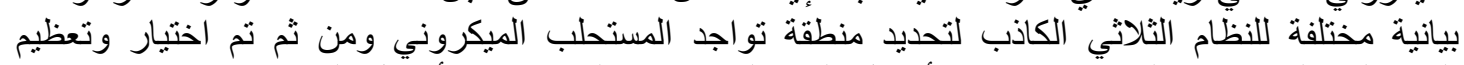

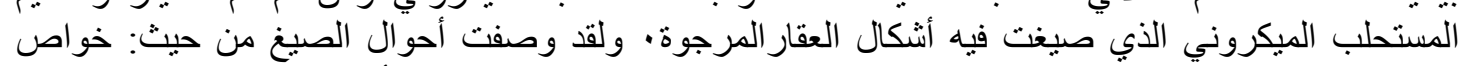

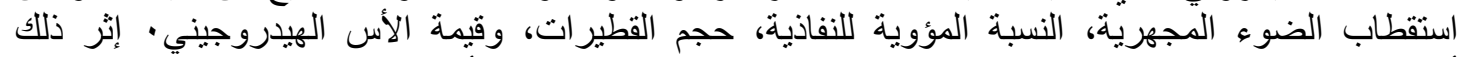

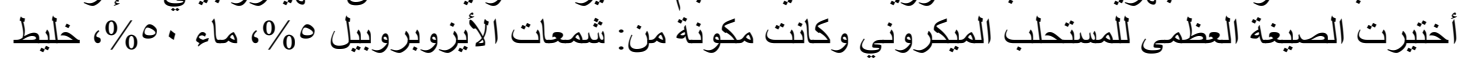

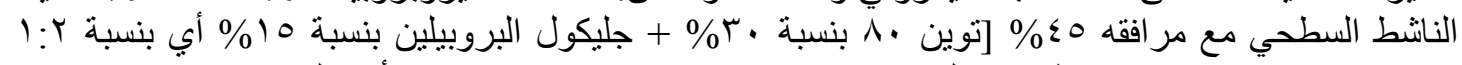

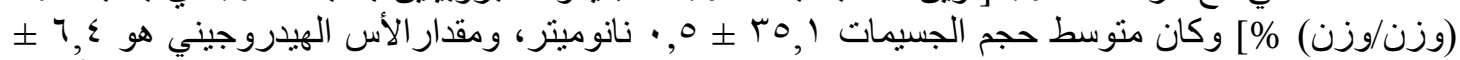

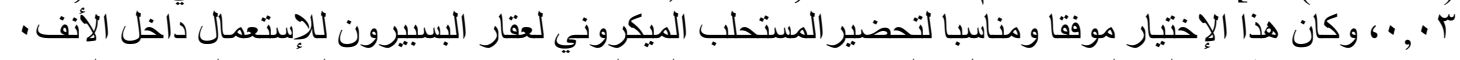

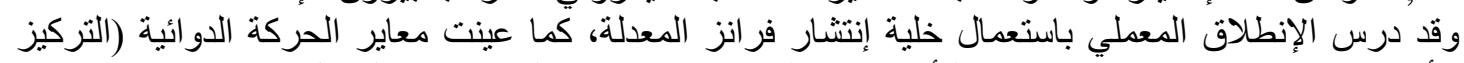

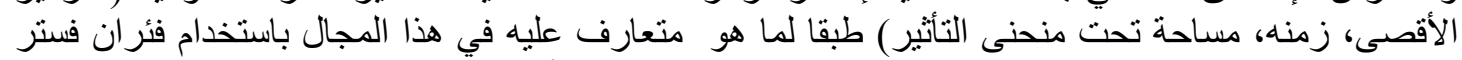

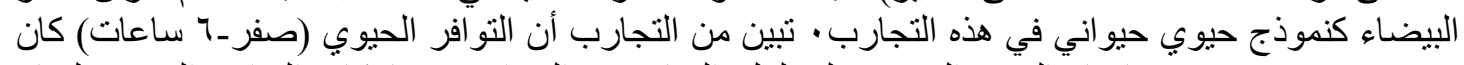

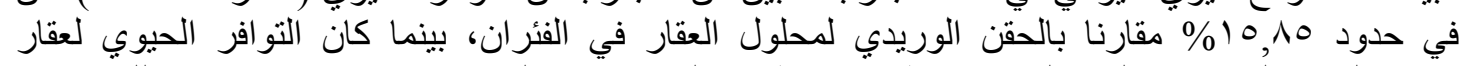

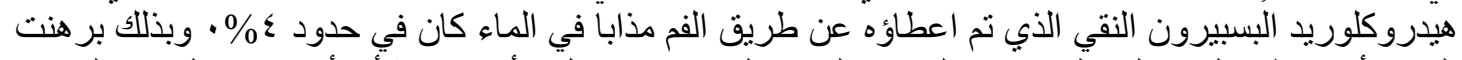

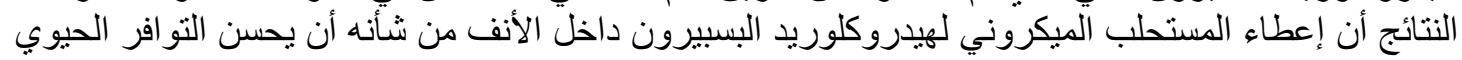

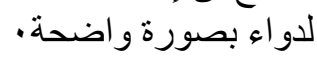
الكلمات المفتاحية: الإيتاء الدوائي داخل الأفه، المستحلب الميكروني، هيدروكلوريد البسبيرون، التوافر الحيوي العلمات 